\title{
The Correlation of Resilience and Anxiety in the Candidate Burn Patients for Skin Grafting
}

\author{
Mahnaz Seyedoshohadaee ${ }^{1}$, Aida Seraj ${ }^{2}$, Hamid Haghani ${ }^{3}$
}

\begin{abstract}
Background \& Aims: Burns affect all aspects of life. In fact, burn victims face various problems and the incidence affects their life quality, especially the psychological dimension. The majority of burn victims suffer from psychological disorders after the incident. On the other hand, burn treatment is a prolonged and difficult process associated with painful procedures, physical problems, and deformities, long hospital stays, surgical treatments, and numerous psychological problems. Burn victims deal with a wide range of stressors that severely change their vital signs and may cause irreversible damages to various body systems, including anxiety. People with burn injuries often experience anxiety, which is usually associated with worry, physical changes (e.g., hypertension and increased heart rate), and tension. Pre-surgery anxiety is also one of the experiences of skin graft candidates. In general, anxiety is a physiological reaction that can prevent improvement and increase the need for anesthesia and post-surgical sedatives. In addition, it decreases the body's immune responses and increases the risk of infection in patients. Resilience is a coping strategy that helps individuals deal with stressful situations and survive pathogenic disorders. In fact, resilience is a dynamic process that leads to the manifestation of positive adaptive behaviors in individuals when facing hardship. With this background in mind, this study aimed to determine the relationship between resilience and anxiety in skin graft burn candidates.

Materials \& Methods: In this descriptive, correlational, and cross-sectional study, we selected samples using continuous sampling based on the inclusion criteria. The participants included skin graft candidates and the research setting was Mottahari Burns Hospital affiliated to Iran University of Medical Sciences. The sample size was determined at a $95 \%$ confidence interval and $80 \%$ test power while assuming a minimum correlation coefficient of 0.25 between resilience and anxiety of skin graft burn candidates following quantification in the formula. After receiving an introduction letter from the nursing and midwifery school and a license from the ethics committee of the university, the researcher referred to the mentioned hospital and explained the research objectives to supervisors and head nurses to gain their agreement and consent before sampling. In total, 130 subjects were selected including 65 men and 65 women in an age range of 18-60 years. Continuous sampling was carried out for one month (June $21^{\text {st }}$-July $22^{\text {nd }}, 2019$ ). It is notable that codes were used instead of names, and the research objectives were explained to the participants prior to the study. In addition, written informed consent was obtained from the participants or one of the immediate family members. Research tools included: 1) demographic characteristics questionnaire, Beck's anxiety inventory (BAI), and the Connor-Davidson Resilience Scale (CDRISC), which were filled 20-30 minutes before the surgery. In addition, data analysis was performed in SPSS version 16 using descriptive and inferential statistics in the form of a table and numerical indexes to describe research units. Moreover, mean and standard deviation, as well as Pearson's correlation coefficient, analysis of variance, and independent t-test were applied to analyze the data.

Results: In this study, $66.2 \%$ of the patients received a resilience score above 50 and a mean resilience score of $64.57 \pm 22.25$ was obtained. On the other hand, the mean anxiety score of $45.4 \%$ of the patients was extremely low $(12.88 \pm 10.45)$, and reverse, a significant correlation was observed between the resilience and anxiety of the participants. In other words, an increase in the resilience score of the participants led to a decrease in their anxiety levels $(\mathrm{r}=-0.0808, \mathrm{P}<0.001)$. The results were also indicative of a significant relationship between resilience and

1. Instructor, Nursing Care Research Center, Department in Internal-Surgical Nursing, School of Nursing and Midwifery, Iran University of Medical Sciences, Tehran, Iran

2. MS Student in Nursing, Department of Medical-Surgical Nursing, School of Nursing and Midwifery, Iran University of Medical Sciences, Tehran, Iran (Corresponding author) Tel: +989124918720 Email: aida.seraja @ gmail.com 3. Instructor, Department of Biostatistics, School of Health, Iran University of Medical Sciences, Tehran, Iran
\end{abstract}


the variables of the level of education $(\mathrm{P}<0.001)$, economic status $(\mathrm{P}=0.001)$, occupational status $(\mathrm{P}=0.02)$, and place of residence $(\mathrm{P}=0.035)$. Furthermore, a significant association was found between the participants' anxiety and the variables of the level of education $(\mathrm{P}=0.004)$, economic status $(\mathrm{P}=0.011)$, occupational status $(\mathrm{P}=0.03)$, and place of residence $(\mathrm{P}=0.016)$.

Conclusion: According to the results of the study, there was a reverse, significant correlation between resilience and anxiety, meaning that an increase in the resilience score led to a decrease in patients' anxiety. In other words, the higher the resilience of patients, the lower their anxiety. Overall, skin graft burn candidates had low anxiety levels and moderate resilience. According to the results of the study, it is recommended that resilience be taught as a supplementary action along with other therapeutic approaches to reduce anxiety in burn victims before a skin graft. Moreover, due to the fact that the rate of resilience was lower in illiterate and low-income people, it is necessary to empower burn candidates to adapt to the conditions, prepare them before skin graft surgery, and prevent complications before, during, and after surgery. By doing so, we can increase resilience and decrease anxiety in these individuals. Our findings can help nursing managers hold in-service educational classes to emphasize the importance of resilience in a decrease of pre-surgical anxiety and increase their life quality.

Keywords: Resilience, Anxiety, Skin Graft, Burn

\section{Conflict of Interest: No}

How to Cite: Seyedoshohadaee M, Seraj A, Haghani H. The Correlation of Resilience and Anxiety in the Candidate Burn Patients for Skin Grafting. Iran Journal of Nursing. 2020; 32(122):69-79.

Received: 16 Nov 2019

Accepted: 12 Feb 2020 


\title{
ارتباط تاب آورى با اضطراب بيماران سوختكى كانديد بيوند يوست
}

\author{
مهناز سيدالشهدايیى '، آيدا سراج'، حميد حقانى
}

جكيده

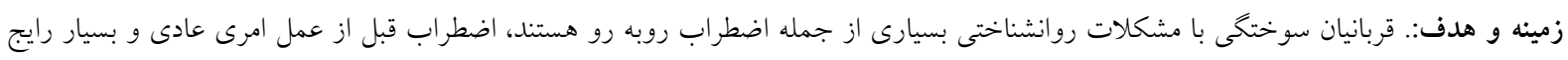

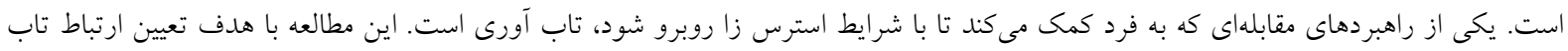

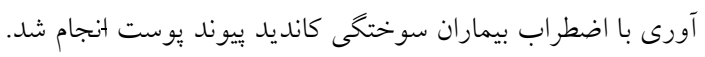

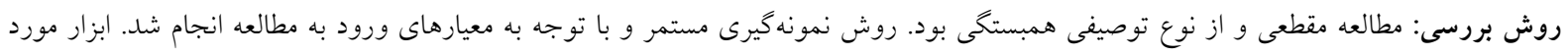

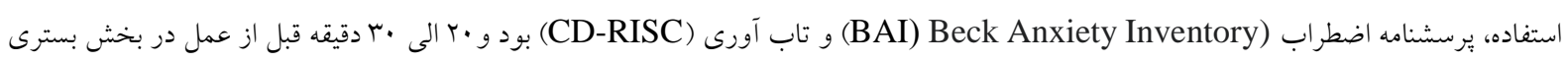

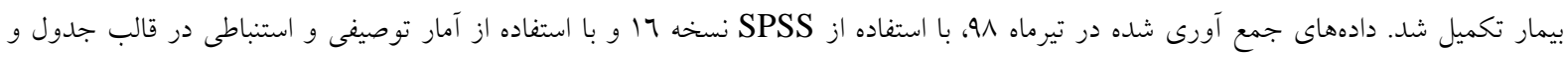

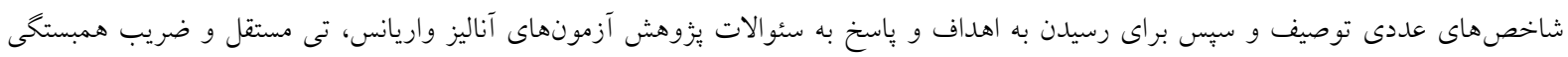
بيرسن حهت تجزيه و تحليل مورد استفاده قرار كرفت فردائ.

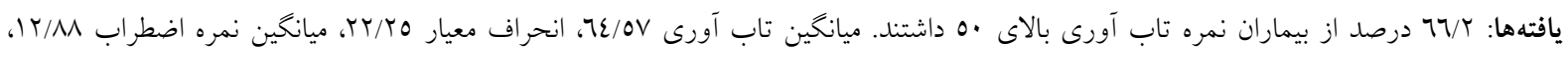

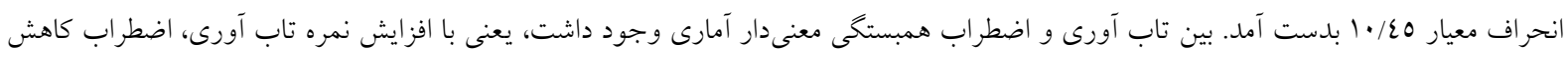

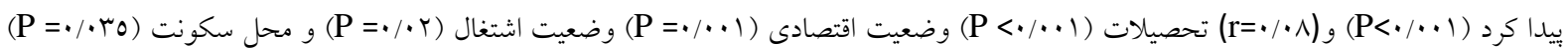

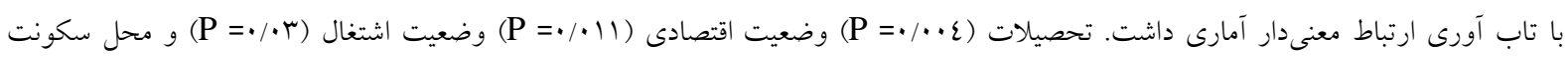

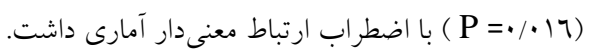

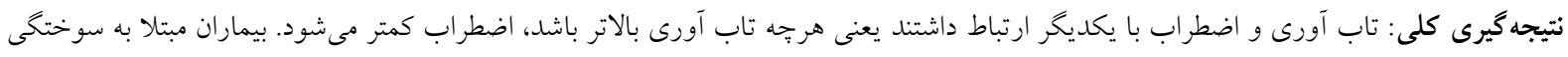

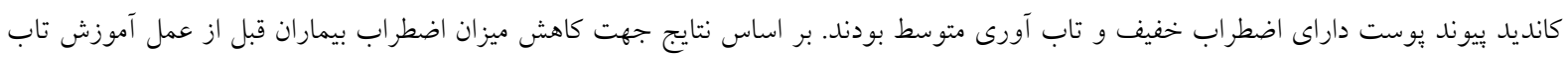
آورى بيشنهاد مى كود..

\section{كليد وازمها :تاب آورى، اضطراب، سوختخى، بيوند بوست}

تعارض منافع: وجود ندارد.

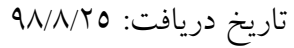

تاريخ بذيرش: سك:

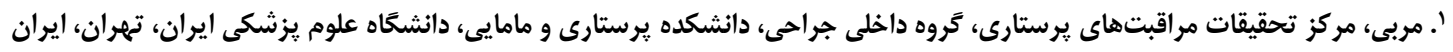


قبل از عمل نه تنها امرى عادى مىباشد بلكه بسيار رايج

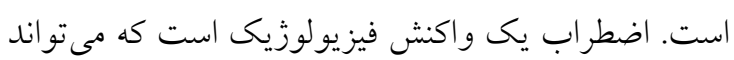

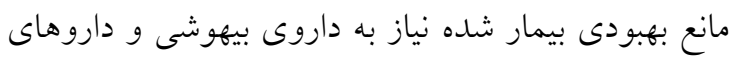

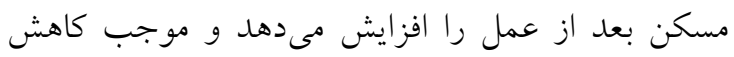

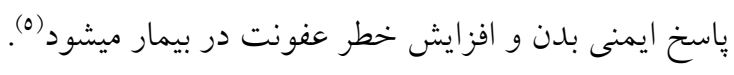
يكى از راهبردهاى مقابلهاى كه به فرد كمك مى كند تا با باليا

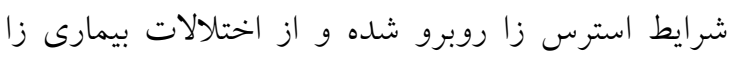

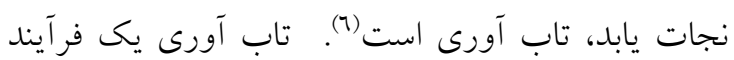

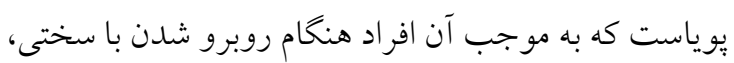

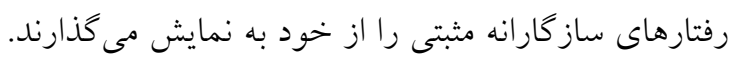

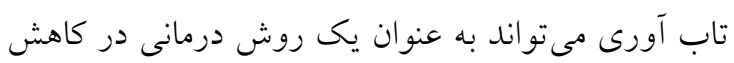

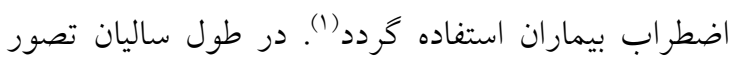
مىشد تابآورى يك ويزگكى خاص در بعضى از افراد

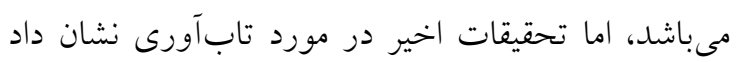

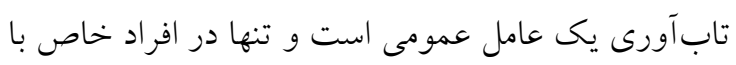

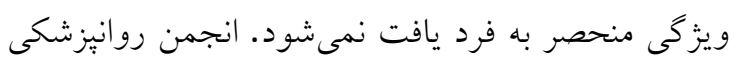

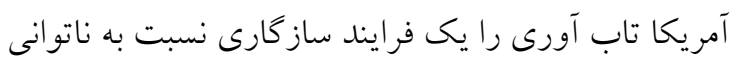

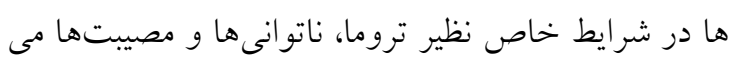

داند.

تاب آورى نقش مهمى در موقعيتهاى استرس زا دارد و

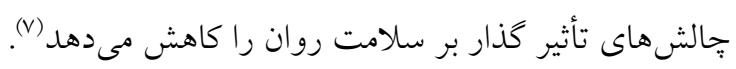

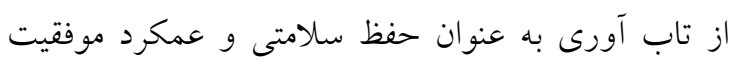

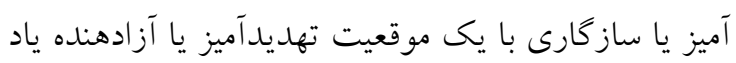

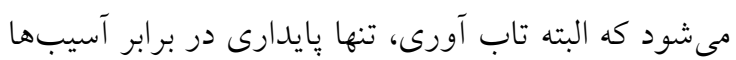

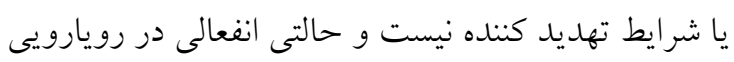
با شرايط خطرناك نمى باشد، بلكه شركت فعال و سازنده در محيط بيرامونى فرد است و توانمندى در برقرارى تعادل زيستى- روانى، در شرايط خطرناك را براى افراد فراهم

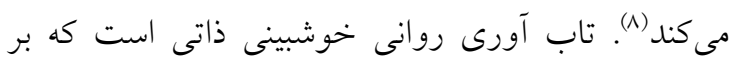

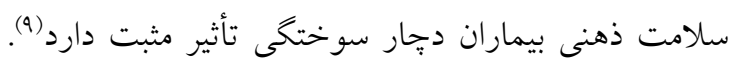

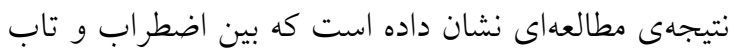

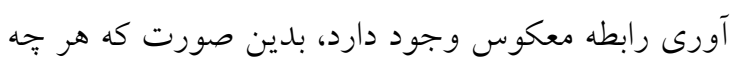

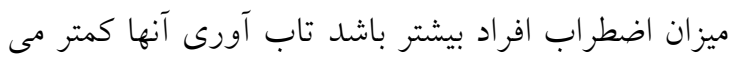

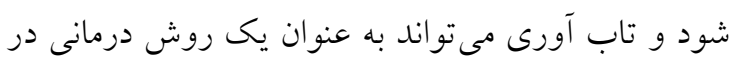

مقدمه

سوختخى تمام جنبه هاى زندگى را تحت تأثير قرار مىدهد. قربانيان سوختخى با مشكلات بسيارى روبه رو هستند و يك ارتباط قوى بين شدت سوختكى و برخى از مشكلات

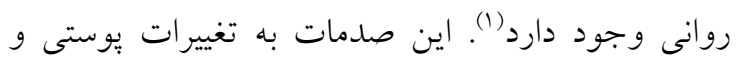
ظاهرى منجر مى شود كه تصوير ذهنى فرد از خود را خدشه دار مى كند. بويزه در مناطق قابل ديد موجب تنش شده و در عملكرد و رفتارهاى بيمار تغيير قابل توجهى ايجاد مى كند بهبود سوختخى يك فرايند طو لانى و دشوار است فرد دجار مشكل در تعامل با محيط اجتماعى و بازگشت به محيط

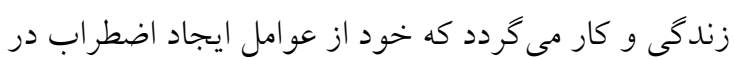
بيمارن سوختخى مىباشد. اضطر اب از ياسخهاى شايع افراد بعد از تروماى جسمى و عاطفى است كه به ميزان زيادى در مبتلايان به سوختكى ديلده مىشود. اضطراب نه تنها از طريق افزايش شدت درد منجر به تخريب عملكرد جسمانى فرد مبتلا به سوختخى مى شود، بلكه عامل تهلديدكننده مهمى نيز در فرايند ترميم زخم مىباشد.

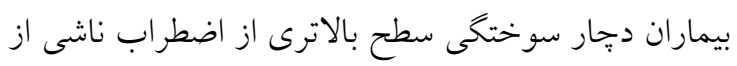

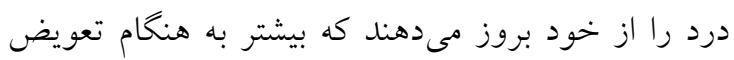
پانسمان ديده مى شود. در واقع توجه به كترل اضطراب در بيماران دجار سوختكى يكى از عناصر ضرورى مراقبت از آنهاست و اضطر اب بيماران منجر به كاهش مشاركت آنها

$$
\text { در برنامههاى درمانى مىشود. }
$$

مراقبتهاى طولانى مدت در بيمارستان در كنار جراحى هاى متعدد ترميمى و همجنين امور توانبخشى و باز توانى وسيع درمان سوختكى از يرهزينهترين بيمارىها مىباشد و جنبههاى اقتصادى و فشارهاى مالى كه بر بيمار و اطرافيان وى دارد خود منجر به اضطراب در بيماران سوختخى مىشود. اضطراب قبل از عمل نيز يكى از اين تجارب در بيماران كانديد عمل جراحى يِيوند يوست است(r). اضطراب قبل

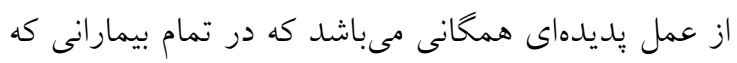
در انتظار عمل جر احى هستند مشاهده مى شود (ع). اضطراب 


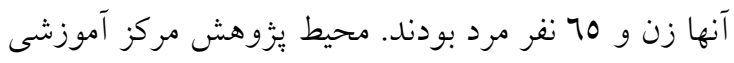
درمانى شهيد مطهرى وابسته به دانشكاه علوم يزشكى ايران

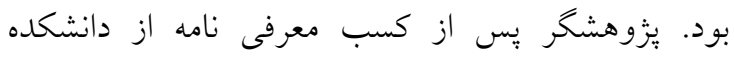

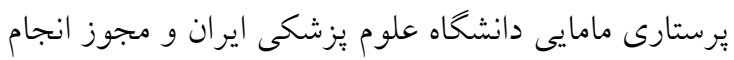

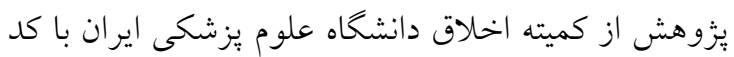

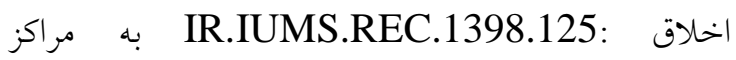
آموزشى درمانى مورد نظر مراجعه كرده شروع به نمونه

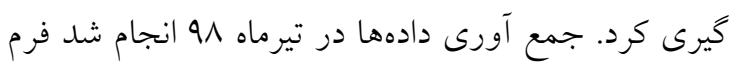

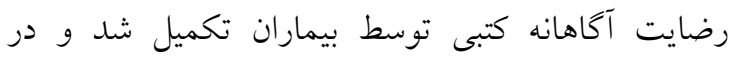

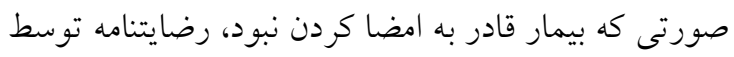
يكى از بستخان درجه يك تكميل و امضا شد. نمونه كيرى به روش مستمر انجام شد و شركت كنندها با توجه به معيارهاى ورود به مطالعه شامل تو انايى خواندن و نوشتن، كانديد عمل جراحى وييوند يوست درج در يرونده، سن

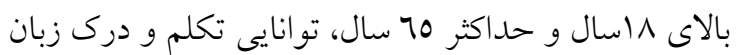
فارسى، عدم مشكل شنوايى و بينايى در برقرارى ارتباط،

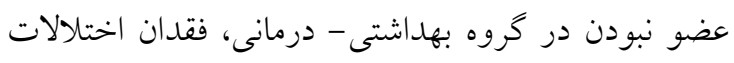

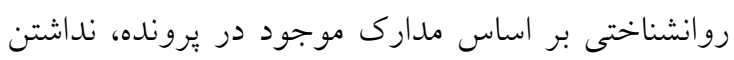

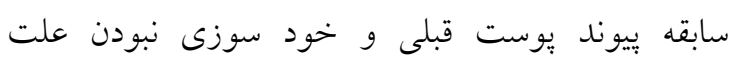

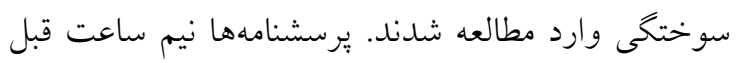

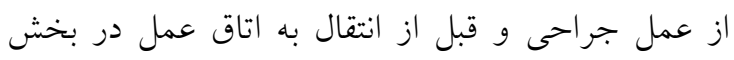
بسترى توسط يُزوهش كر، تكميل شد. در اين مطالعه ابزار

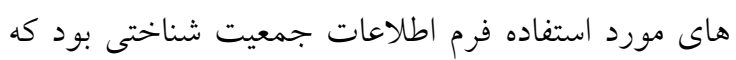
اين فرم شامل سؤالاتى از قبيل سن، جنسيت، وضعيت تأهل، سطح تحصيلات، وضعيت اقتصادى، شغل، تعداد فرزند، محل سكونت و وضعيت بيمه بود. يرسشنامه

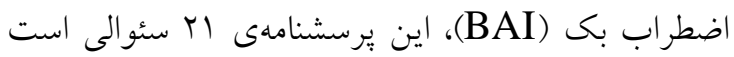

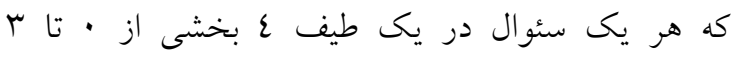

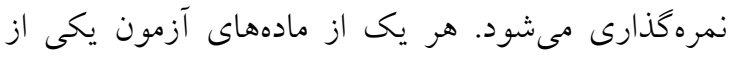

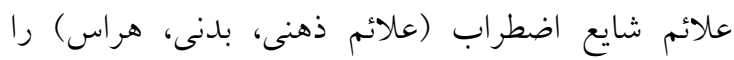
توصيف مى كند. بنابر اين نمره كل اين ترسشنامه در دامنهاى

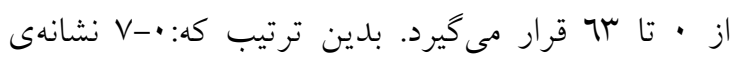
اضطراب خيلى خفيف، 10-1 نشان دهندهى اضطراب

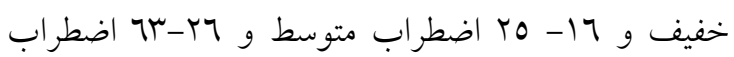

كاهش اضطراب بيماران استفاده گردد(·). در اين ميان مراقبتهاى يرستارى بسيار مهم هستند و و يرستاران

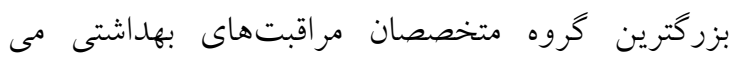

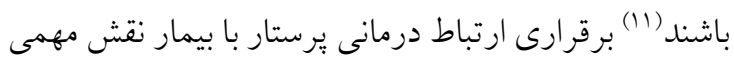

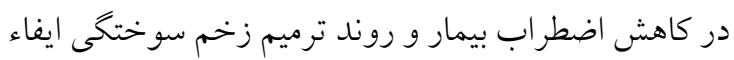

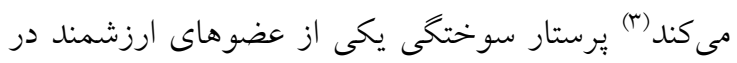

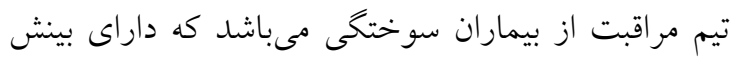
منحصر به فرد و مهارتهاى تخصصى مىباشد كه براى

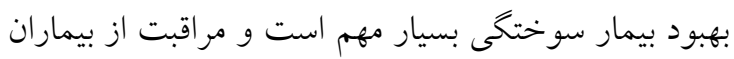
را در سراسر زنجيره بيمارى از دوره حاد تا بهبودى و سلامتى انجام مىدهند. طيف كستردهاى از مهارتها از

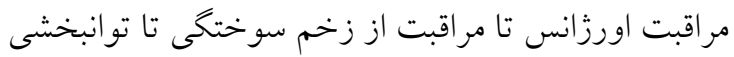
و بهبودى براى ارائه مراقبت در سراسر اين زنجيره مورد

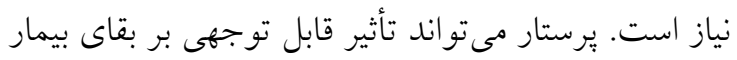

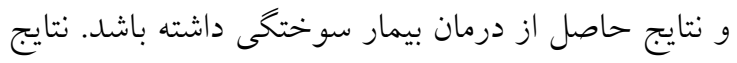
بالينى را مىتوان از طريق فعاليتهاى تحقيقاتى و برنامه

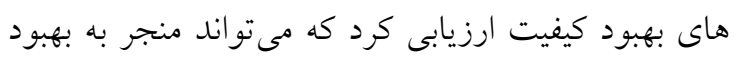

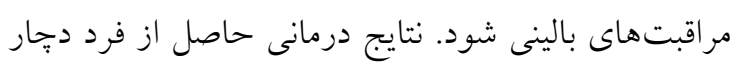

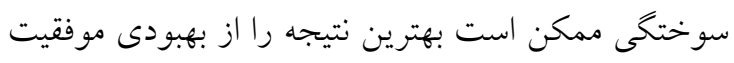

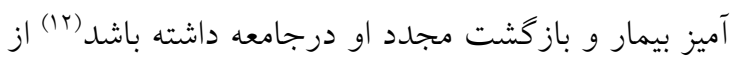
آن جا كه تاب آورى با بهداشت روان، بهزيستى و روان

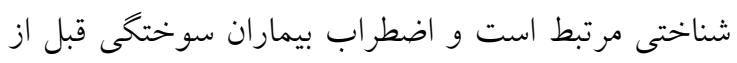

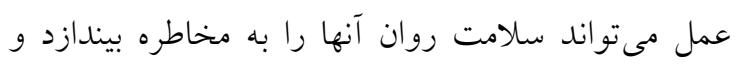

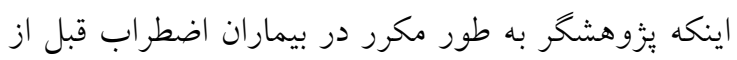

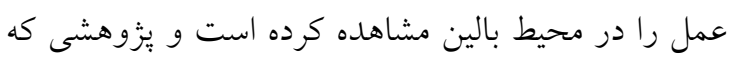

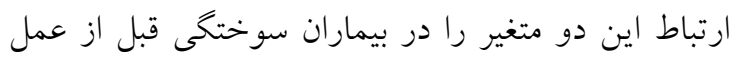

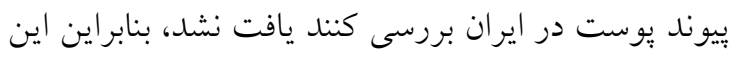

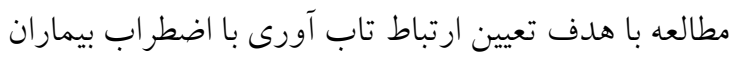
كانديد عمل بيوند يوست را انجام شد.

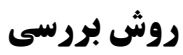

نوع مطالعه در اين يزوهش مقطعى از نوع توصيفى - نوليك

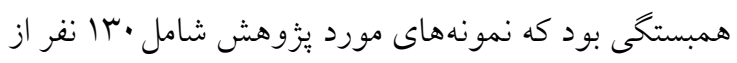

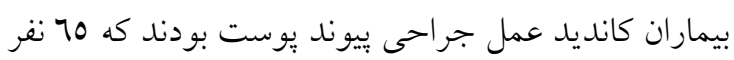


نرم افزار SPSS نسخه 17 با آزمونهاى آمارى آناليز واريانس، تى مستقل و ضريب همبستكى وبيرسون تحليل

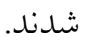

\section{يافتهها}

نتايج نشان داد كه ميانخين سنى بيماران مورد بزوهش

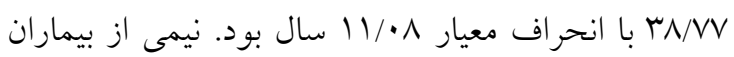

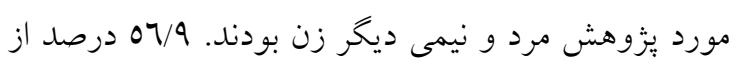

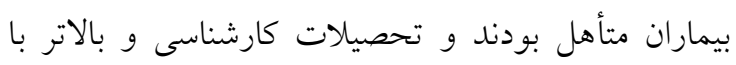

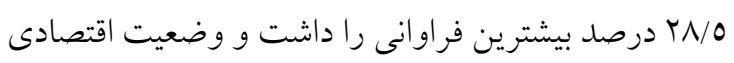

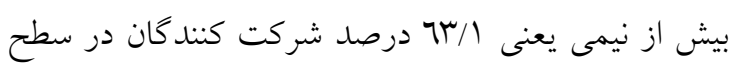

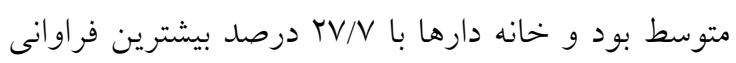

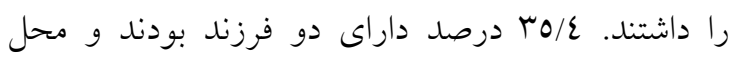

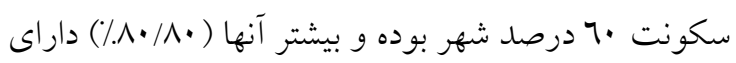

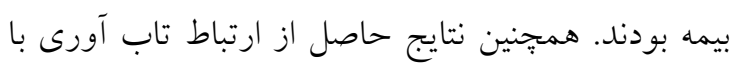

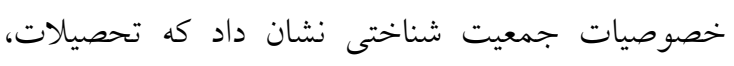

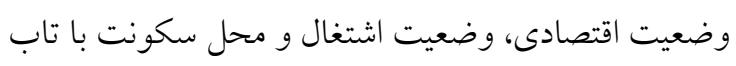

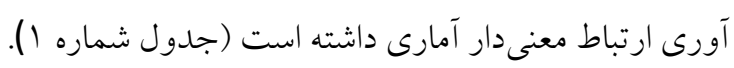

شديد بود (r). يرسشنامه تاب آورى كانرو- ديويدسون CD-) )Scale) (conner-davidson Resilience (RISC

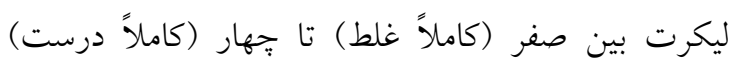

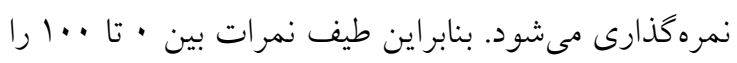

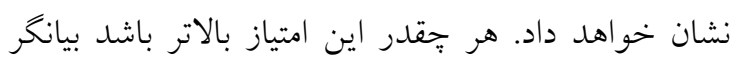

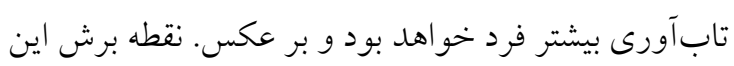

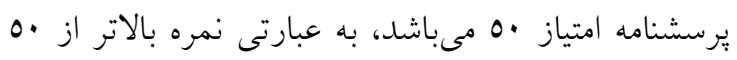

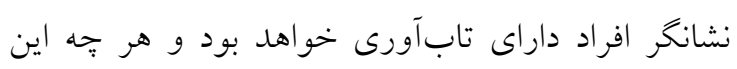

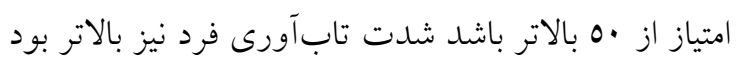

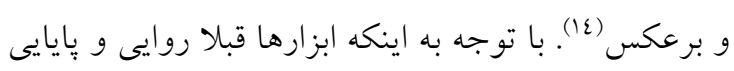

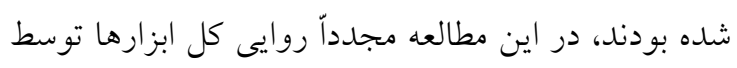

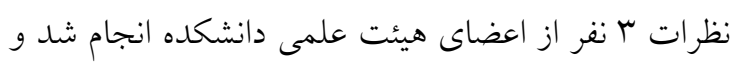

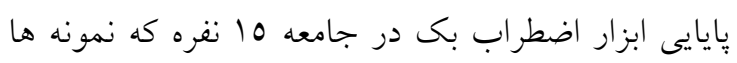

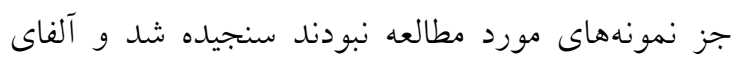

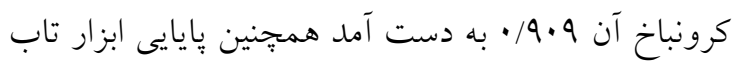

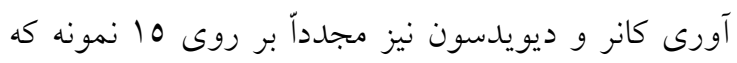
جزء نمونههاى مطالعه نبودند سنجيده شد و آلفاى كرونباخ

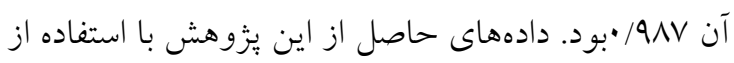

جدول شماره (:.شاخصهاى فردى شركت كنندَّان درمطالعه و ارتباط آنها با تاب آورى و اضطراب

\begin{tabular}{|c|c|c|c|c|c|c|c|}
\hline \multicolumn{2}{|c|}{ اضطر اب } & \multicolumn{2}{|c|}{ تاب آورى } & \multirow[b]{2}{*}{ درصد } & \multirow[b]{2}{*}{ فراوانى } & \multirow{2}{*}{\multicolumn{2}{|c|}{ مشخصات فردى }} \\
\hline نتيجه آزمون & Mean \pm SD & نتيجه آزمون & Mean \pm SD & & & & \\
\hline $\mathrm{F}=90 \varepsilon /$ & $\mid \varepsilon / \wedge \mu \pm 11 / \mu$ & $F=\cdot / 99$ & $7 \cdot / r 1 \pm r \varepsilon / 17$ & Tr/A & m & كمتر از •r & \\
\hline \multirow[t]{3}{*}{$\mathrm{P}=\varepsilon \mid \mathrm{V} / \bullet$} & $\mid r / 1 \mu \pm 11 / 1$ & $\mathrm{P}=\cdot / \varepsilon$ & $70 / \varepsilon r \pm Y r / \Sigma)$ & r. & rq & $r \cdot-r q$ & سن \\
\hline & $1 \cdot / \neg \varepsilon \pm \Lambda / \Lambda \Lambda$ & & $71 / 90 \pm 19 / 10$ & TN/O & rv & $\varepsilon \cdot-\varepsilon q$ & (سال) \\
\hline & $\mid r / \varepsilon r \pm 1 \cdot / \varepsilon 7$ & & $\tau 1 / \Lambda r \pm r r / q \varepsilon$ & IV/V & r & •0 و بالاتر & \\
\hline$t=|/| r \mid$ & $11 / 10 \pm 1 \cdot / 17$ & $t=1 / 9 r T$ & $r / r) \pm r \cdot / 0 r$ & 0. & 70 & 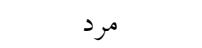 & جنسيت \\
\hline$d f=\mid r \wedge$ & $|r / q| \pm 1 \cdot / V$ & $\mathrm{df}=\mid \Upsilon \wedge$ & $\tau \cdot / \Lambda \varepsilon \pm T r / \varepsilon l$ & 0. & 70 & زن ان & \\
\hline $\mathrm{P}=\cdot / r\urcorner \varepsilon$ & & $\mathrm{P}=.1 .07$ & & & & & \\
\hline $\mathrm{F}=1 / \cdot \mu \mu$ & $11 / N \pm 1 \cdot / N 1$ & $\mathrm{~F}=\Upsilon / \Upsilon \wedge \mathrm{N}$ & $79 / 11 \pm r r / 79$ & $1 \ldots$ & $\mu$ & مجرد & \\
\hline \multirow[t]{3}{*}{$\mathrm{P}=\cdot / \mu$} & $1 T / \pi T \pm 1 \cdot / 9 T$ & $\mathrm{P}=\cdot / \cdot v r$ & $7 T / \cdot V \pm r / / 07$ & $r \pi / \Lambda$ & $v \varepsilon$ & متأهل & وضعيت \\
\hline & $\mid V / \cdot 1 \pm 9 / 0 \varepsilon$ & & $00 / 0 \varepsilon \pm r r / 19$ & $07 / 9$ & $1 \varepsilon$ & همسر فوت شده & تأهل \\
\hline & $1 \varepsilon / 77 \pm 7 / \varepsilon 7$ & & $\Delta r / \cdot 1 \pm r / / 0 r$ & $1 \cdot 1 \wedge$ & 11 & متار كه & \\
\hline \multirow[t]{3}{*}{$\mathrm{F}=$ ONOY } & $11 / \cdot 9 \pm 1 \cdot / 11$ & $\mathrm{~F}=1 \cdot / \wedge \mathrm{TV}$ & $\Sigma q / \Lambda \Lambda \pm r I / \Sigma V$ & $1 / 0$ & ro & زيردييلم & \\
\hline & $11 / \varepsilon V \pm 1 \cdot / r T$ & $\mathrm{P}<\cdot / \cdot \cdot 1$ & $79 / 0 r \pm r I / \cdot 1$ & $1 \cdots$ & $0 \wedge$ & دييلم & تحصيلات \\
\hline & $1 \cdot N r \pm 9 / 9 r$ & & $79 / 2 r \pm 19 / 11$ & $r 7 / q$ & rv & كارشناسى وبالاتر & \\
\hline
\end{tabular}




\begin{tabular}{|c|c|c|c|c|c|c|c|}
\hline \multirow{3}{*}{$\begin{array}{l}\mathrm{F}=\{/ 79 r \\
\mathrm{P}=\cdot / \cdot 11\end{array}$} & $\mid V / \cdot 1 \pm 1 \cdot / r \varepsilon$ & $\mathrm{F}=\mathrm{V} / 071$ & $01 / .0 \pm r r / 09$ & $\varepsilon / 7$ & IV & ضعيف & وضعيت \\
\hline & $\mid r / V T \pm 11 / 11$ & \multirow[t]{2}{*}{$\mathrm{P}=\cdot / \cdot \cdot 1$} & $T r / \mu \pm r r / \varepsilon r$ & TN/O & NT & متوسط & اقتصادى \\
\hline & $\Lambda / \varepsilon \pm 7 / q r$ & & $V T / r q \pm 17 / 01$ & $1 \ldots$ & m & خوب & \\
\hline \multirow{6}{*}{$\mathrm{P}=\cdot / \cdot r$} & $10 / 7 V \pm 11 / \varepsilon \varepsilon$ & \multirow{6}{*}{$\mathrm{P}=\cdot / \cdot r$} & $0 \wedge / 79 \pm r \varepsilon / V \varepsilon$ & $14 / 1$ & r & خانه دار & \\
\hline & $9 / r \pm N / \cdot q$ & & $V T / 17 \pm I V / T \varepsilon$ & $7 \pi / 1$ & rT & كارمند & \\
\hline & $19 / 79 \pm 11 / 71$ & & $\sum q / \Gamma T \pm Y r / \cdot \tau$ & TH/A & 10 & كارگر & وضعيت \\
\hline & $1 \cdot / r 7 \pm N / T r$ & & $V \cdot / V q \pm I V / \Lambda \varepsilon$ & $1 \ldots$ & rq & آزاد & اشتغال \\
\hline & $|\varepsilon / 0 r \pm| \varepsilon /||$ & & $\tau r / \varepsilon V \pm r V / l$ & $r V / V$ & $\wedge$ & بيكار & \\
\hline & $1 \cdot / 77 \pm 1 / 90$ & & $77 / 17 \pm r o / r V$ & $r \cdot$ & 7 & بازنشسته & \\
\hline \multirow{5}{*}{$\mathrm{P}=\cdot / \tau \cdot V$} & $1 \cdot / \mu 1 \pm 11 / \Lambda$ & \multirow{5}{*}{$\begin{array}{l}\mathrm{F}=1 / r r \varepsilon \\
\mathrm{P}=\cdot / r \cdot r\end{array}$} & $V 1 \pm r l / 20$ & $17 / r$ & 17 & . & \multirow{5}{*}{ فرزداد } \\
\hline & IT/AT \pm V/OY & & $T r / 2 q \pm r 1 / \cdot r$ & $T M / T$ & rI & 1 & \\
\hline & $\mid r / T O \pm 1 \cdot / 7 V$ & & $T r / 0 r \pm r / / \varepsilon$ & ro/ & ro & r & \\
\hline & $|\Lambda / v \varepsilon \pm| 1 / N \mid$ & & $\Delta r / V T \pm r r / \Lambda$ & $10 / \%$ & 10 & r & \\
\hline & $11 / 1 \pm 9 / 1 r$ & & $T E / Q T \pm r r / 97$ & $1 \cdot / 1$ & 1. & $\varepsilon$ & \\
\hline$t=r / \varepsilon$ or & $1 \varepsilon / \varepsilon \pm 1 \cdot / 90$ & $\mathrm{t}=r /|r|$ & $T Y / T V \pm Y T / V T$ & r & VA & شهر & محل \\
\hline df = & $q / V 1 \pm q / r 1$ & $\mathrm{df}=11 \cdot / \mathrm{rq}$ & $v \cdot / 20 \pm 19 / \cdot v$ & $1 \ldots$ & $\varepsilon V$ & مركز استان & سكونت \\
\hline $\mathrm{P}=\cdot / \cdot 17$ & & $\mathrm{P}=\cdot / \cdot \mathrm{r}_{0}$ & & & & & \\
\hline $\mathrm{t}=\cdot / 0 \mathrm{rA}$ & $\mid r / 1 r \pm 1 \cdot / 01$ & $\mathrm{t}=\cdot / 7 \cdot \wedge$ & $\tau r / Q \Lambda \pm r Y / 1 \Lambda$ & 7. & 1.0 & دارد & وضعيت \\
\hline $\mathrm{df}=\mid r \wedge$ & $11 / 10 \pm 1 . / 17$ & $\mathrm{df}=\mid \uparrow \wedge$ & $T V / \cdot 1 \pm r Y / \Lambda r$ & $r / \Lambda$ & ro & 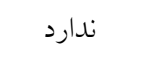 & بيمه \\
\hline $\mathrm{P}=\cdot / 091$ & & $\mathrm{P}=\cdot / 00 \varepsilon$ & & & & & \\
\hline
\end{tabular}

كرده بودند و ع/ ع درصد از بيماران مورد يزوهش تاب

آورى در سطح خيلى خفيف داشتند (جدول شماره ب).

جدول شماره ؟ّ: توزيع فراوانى، ميانكَين و انحراف معيار

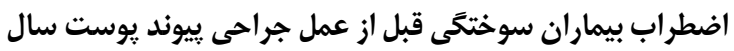

1791

\begin{tabular}{|c|c|c|}
\hline درصد & فراوانى & اضطر اب \\
\hline$\varepsilon 0 / \varepsilon$ & 09 & خيلى خفيف \\
\hline$r Y / 0$ & rA & خفيف \\
\hline $17 / r$ & rI & متوسط \\
\hline $17 / 9$ & rt & شديد \\
\hline $1 \ldots$ & $1 \pi$. & جمع كل \\
\hline \multicolumn{2}{|c|}{$\mid r / \Lambda \Lambda \pm 1 \cdot / 20$} & انحراف معيار 土 ميانخين \\
\hline \multicolumn{2}{|c|}{ - } & بيشينه - كمينه \\
\hline
\end{tabular}

نتايج نشان داد كه اضطراب ع/2ع درصد از بيماران مورد يُزوهش در سطح خيلى خفيف بود. ميانخين نمره اضطراب

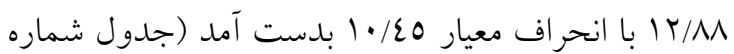

نتايج نشان داد كه تحصيلات ( (ع=•/p)، وضعيت

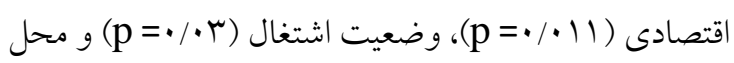
سكونت (17 (1) p = با اضطراب ارتباط معنىدار آمارى

$$
\text { داشته است (جدول شماره Y). }
$$

جدول شماره r: توزيع فراوانى، ميانكَين و انحراف معيار تاب

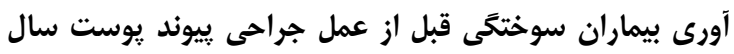

1791

\begin{tabular}{|c|c|c|}
\hline درصد & فراوانى & تاب آورى \\
\hline Tr/A & $\varepsilon \varepsilon$ & لم و كمتر \\
\hline $77 / r$ & $\wedge 7$ & بالاى •0 \\
\hline $1 \cdots$ & $1 \%$ & جمع كل \\
\hline \multicolumn{2}{|c|}{$T \varepsilon / O V \pm T r / T O$} & انحراف معيار 土 ميانخين \\
\hline \multicolumn{2}{|c|}{$10-90$} & بيشينه- كمينه \\
\hline
\end{tabular}

نتايج يزووهش همجنين نشان دهنده آن بود كه T/T درصد

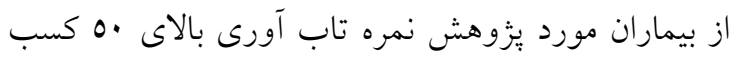


دار آمارى داشته است. مقايسه دو به دو نشاندهنده آن بود

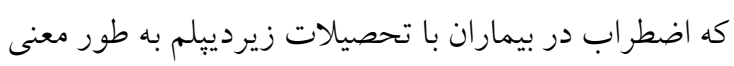

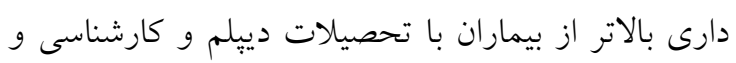

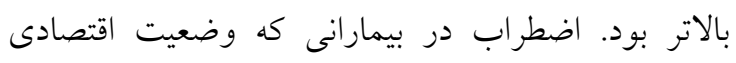

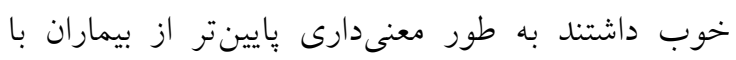

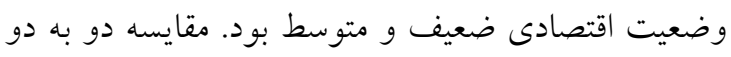

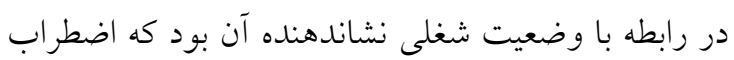

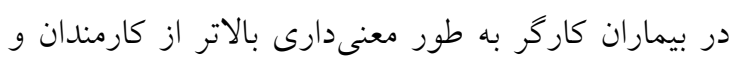

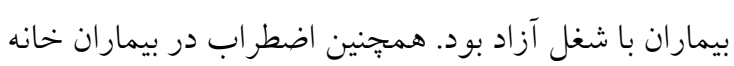
دار نيز به طور معنىدارى بالاتر از بيماران با شغل كارمند و آزاد بود و در ساير موارد اين اختلاف معنى بهدار نبود.

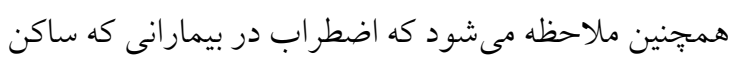

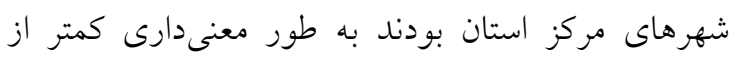

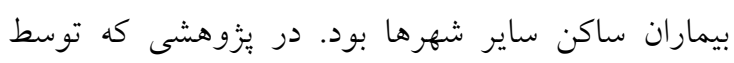
Palmu

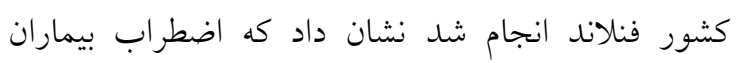
سوختخى در سطح متوسط مىباشد و با جنسيت بيماران

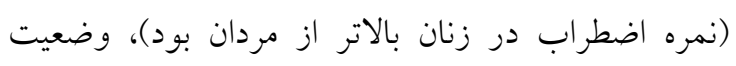

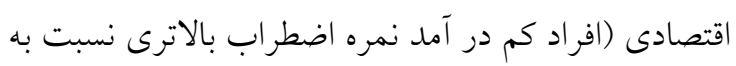

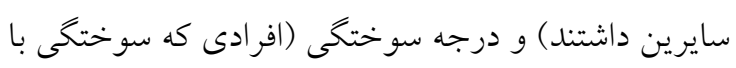

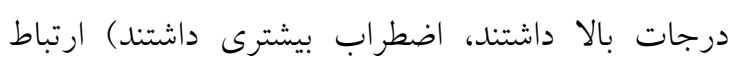
دارد(1). نتايج اين مطالعه با بزّوهش حاضر در رابطه با تأثير وضعيت اقتصادى بر اضطراب مطابقت دارد و با ديخر

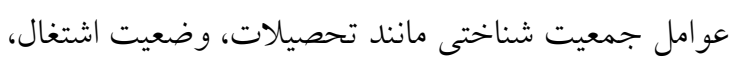

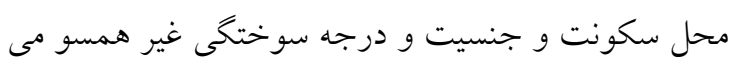

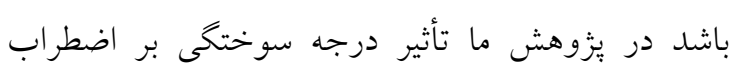
بيمار ان مورد بررسى قرار نكرفته بود.

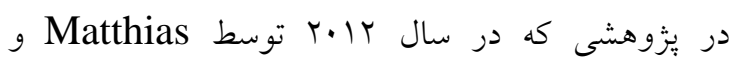

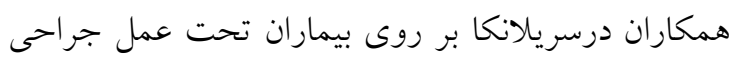

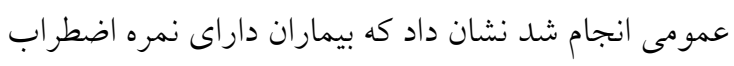

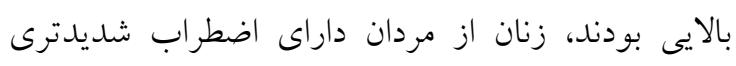

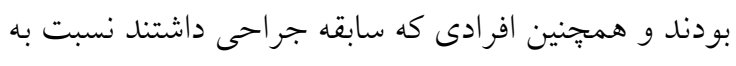

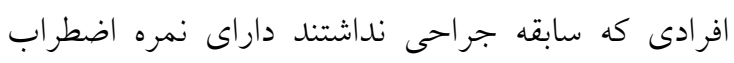

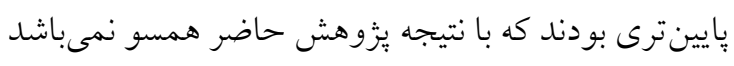

ץ). بين تاب آورى و اضطراب همبستكى معنىدار آمارى

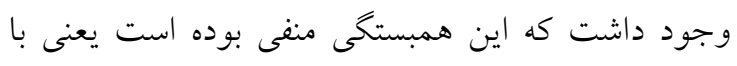

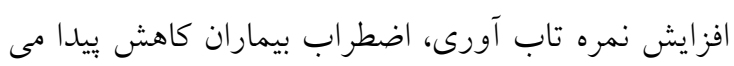
كرد (r=・・・

\section{بحث و نتيجه كيرى}

نتايج ئزوهش حاضر نشان داد كه اضطراب بيشتر بئر بيماران

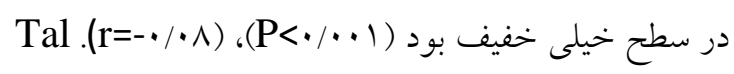

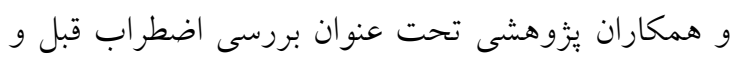

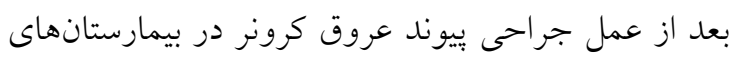

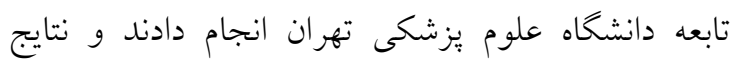

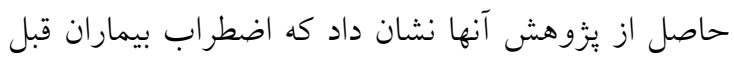

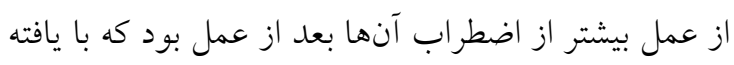

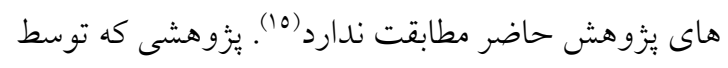
Alvi

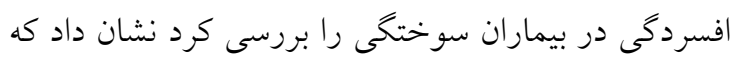

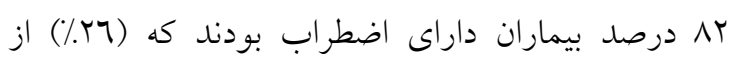

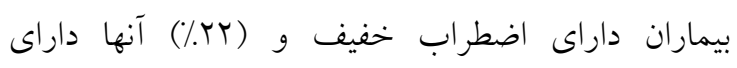
اضطراب متوسط و (عَّ/) بيماران داراى اضطراب شديد

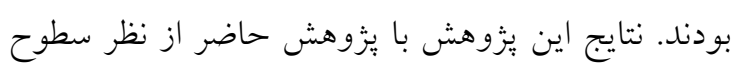

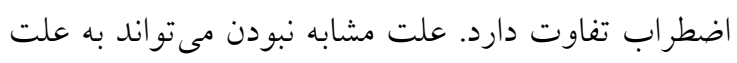

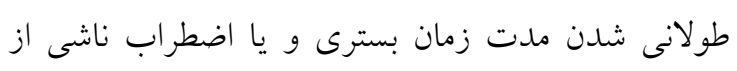

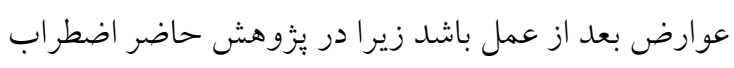

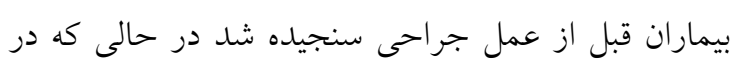

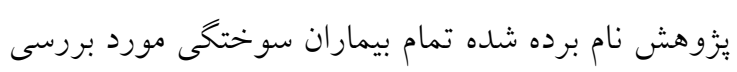

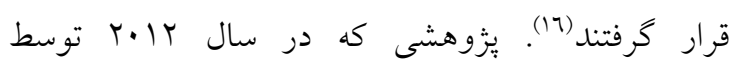
Matthias

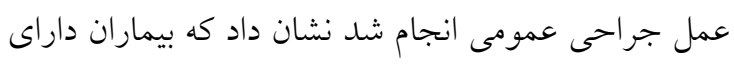

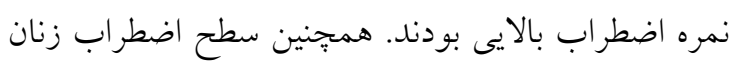

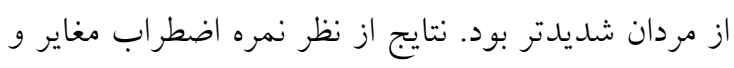

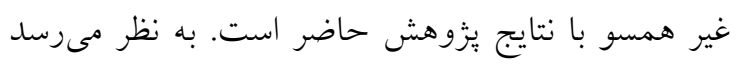

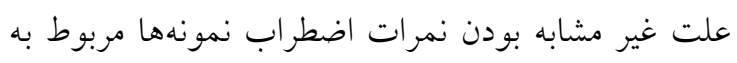
نوع عمل جراحى باشد (iv).

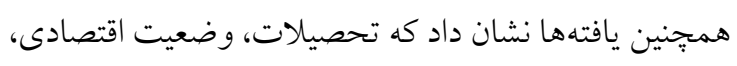

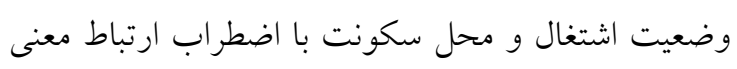


و نكرانى نسبت به اختلال تصوير از بدن رابطه معكوس وجود داشت و بين اضطراب و نكرانى نسبت به اختلال

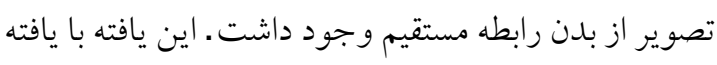

هاى يزّوهش حاضر همسو بود (II).

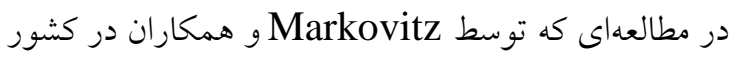

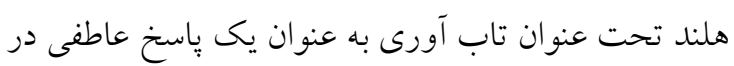
زمان تشخيص و جراحى در زنان مبتلا به سرطان انجام شد، نشان داد كه اضطراب، افسردگى در بيماران مبتلا به سرطان قبل از عمل جراحى در سطح بالاترى نسبت به

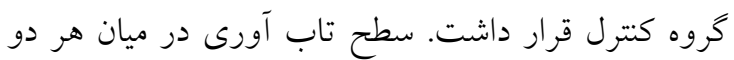
كروه كنترل و آزمون مشابه بود و همريجنين ارتباطى ميان

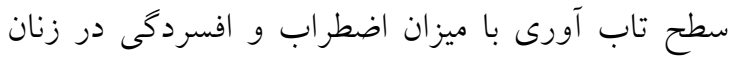
مبتلا به سرطان وجود نداشت(rr). نتيجه اين مطالعه با نتيجه

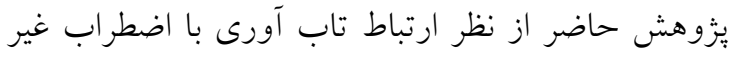

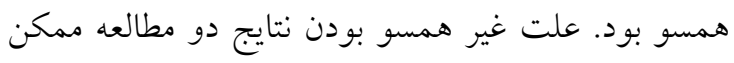

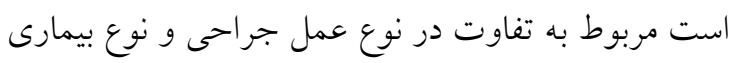
و يا زمان انجام مطالعه مطالعه باشد.

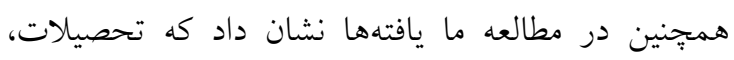

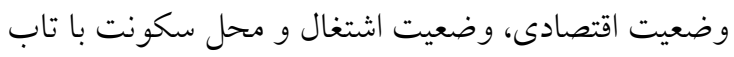
آورى ارتباط معنى دار آمارى داشته است. مقايسه دو به دو

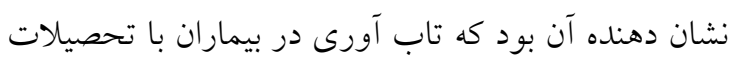

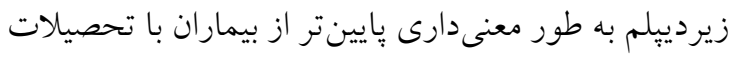

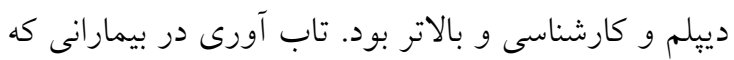
وضعيت اقتصادى ضعيف داشتند به طور معنى دارى كمتر از بيماران با وضعيت اقتصادى متوسط و خوب بود و

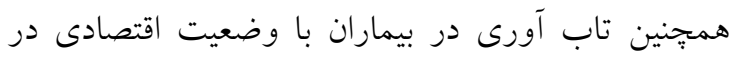
سطح متوسط نيز به طور معنىدارى كمتر از بيماران با وضعيت اقتصادى خوب بود. مقايسه دو به دو در رابطه با وضعيت اقتصادى نشاندهنده آن بود كه تاب آورى در بيماران خانهدار به طور معنىدارى كمتر از كارمندان و بيماران با شغل آزاد بود. همجنين تاب آورى در بيماران با لبان شغل كارگر نيز به طور معنىدارى كمتر از بيماران با شغل

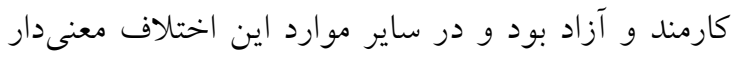
نبود. همتجنين ملاحظه مى شود كه تاب آورى در بيمارانى
زيرا در اين يزوهش فاكتورهاى جمعيت شناختى ديخر

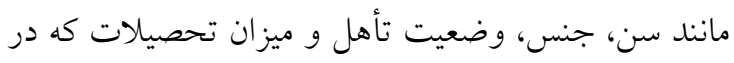

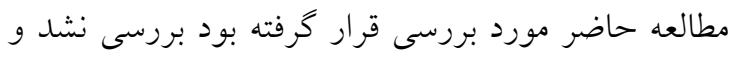

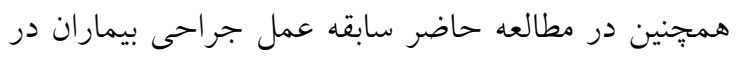
نظر كرفته شده بود كه در مطالعه فوق اين فاكتور مورد

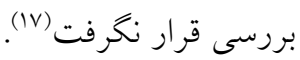
Yang و همكارانش در سال ع الج مطالعهاى در بيماران سوختكى تحت توانبخشى در بيمارستانى در شانگهاى

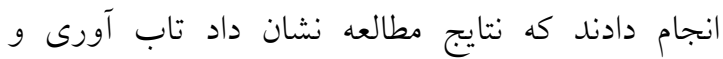
اضطراب همبستكى معنى دار آمارى داشتند كه اين همبستخى منفى بوده است يعنى با افزايش نمره تاب آورى، اضطراب بيماران كاهش ييدا مى كند، تاب آورى بيماران در سطح متوسط بود و جنسيت، وضعيت تأهل، اشتغال، سطح تحصيلات و شيوه برخورد كاركنان عوامل موثر بر تاب آورى بودند. اين مطالعه از نظر تأثيرجنسيت

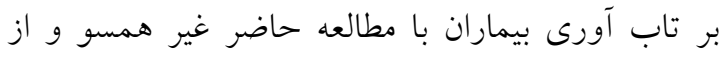

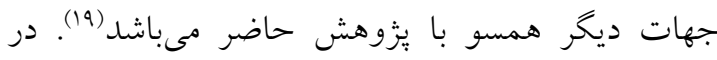

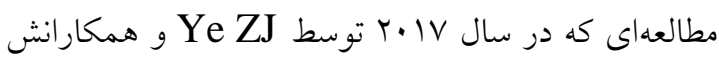
بر روى بيماران جينى مبتلا به سرطان ريه، معده و و

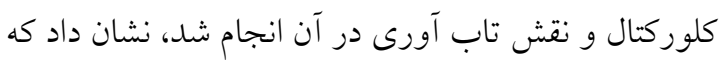

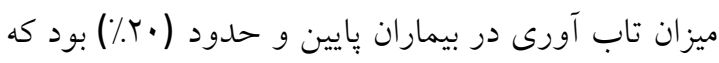
با مطالعه حاضر همسو نيست شايد غير همسو بودن دو

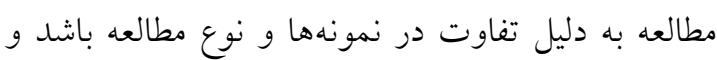

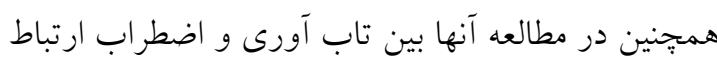
معنى دارى وجود نداشت كه در اين رابطه هم نتايج غير نهاب

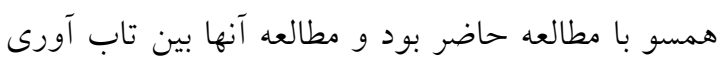

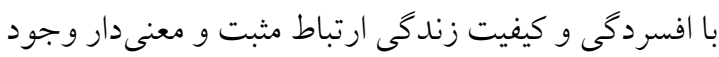

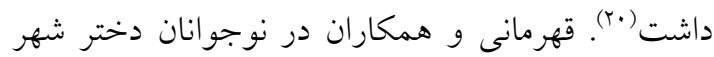
تهر ان نشان داد كه ماتريس همبستخى بين متغيرهاى بيش بين با افزايش تاب آورى روانى، ميزان نكرانى افراد

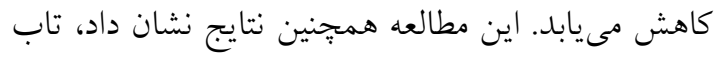

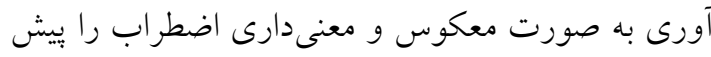

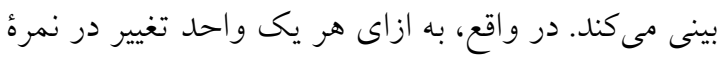

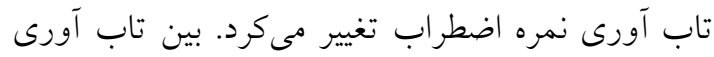


سوختكى كانديد عمل جراحى بيوند يوست جهت تطابق

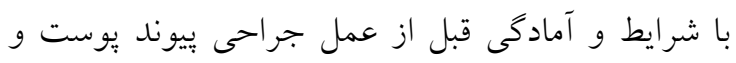

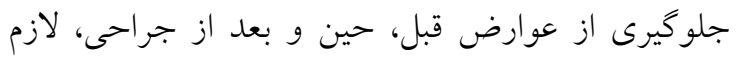

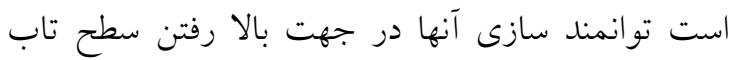
آورى و كاهش اضطر اب آنها مورد استفاده قرار كيرد. يافته

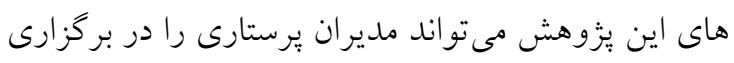

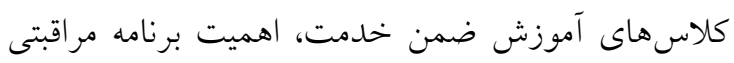

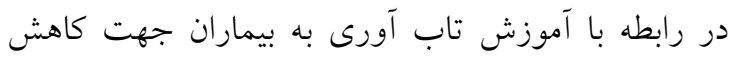
اضطراب قبل از عمل و افزايش كيفيت زندگى كمى نمايد از محدوديتهاى اين يزوهش مىتوان به مسائل اقتصادى وهزينه هاى درمان، اختلالات شخصيتى و روانى ناشناخته بيمار ان اشاره كرد كه ممكن بود بر روى اضطر اب آنان تأثير

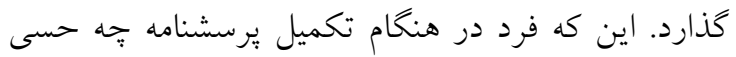
در مورد بيمارى خود داشته باشد و يا جهه اندازه مشكلات

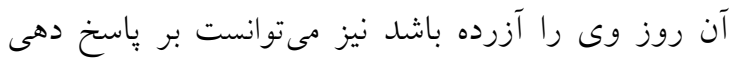

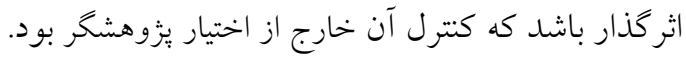
با توجه به اينكه اين مطالعه توصيفى بود بيشنهاد مى بـود

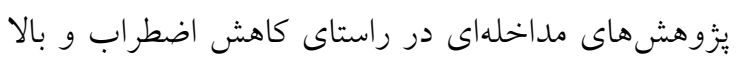

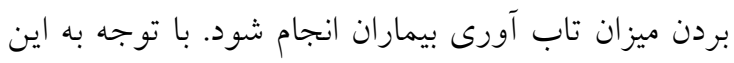

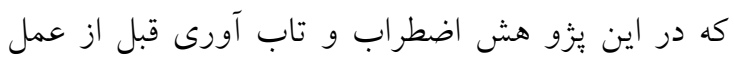

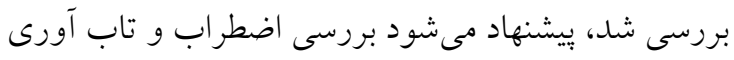

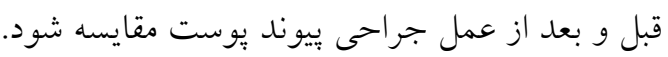

تعارض منافع: نويسندكان هيج گونه تعارض منافعى را

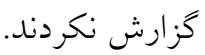

\section{تقدير و تشكر}

اين مقاله نتايج بر كرفته از بِيان نامه كارشناسى ارشد

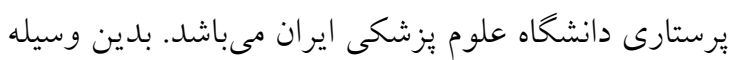

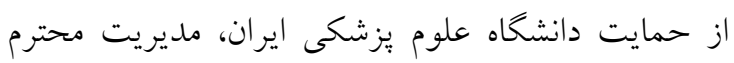
مركز سوانح سوختكى شهيد مطهرى و تمامى بيماران

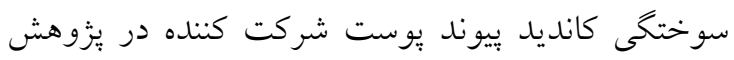
حاضر كه ما را در انجام رساندن اين مهم يارى نمودهاند، نهايت تشكر و قدردانى را داريم.
كه ساكن شهرهاى مركز استان بودند به طور معنىدارى بالاتر از بيماران ساكن ساير شهرها بوده در يزوهشى كه در سال 17 17 توسط مسعود و همكاران

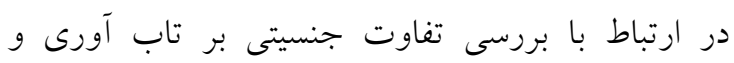

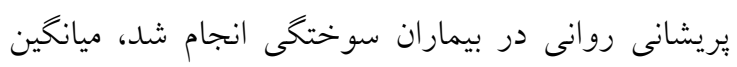

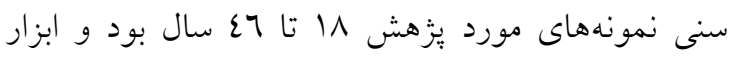
سنجش تاب آورى Young,s \&Wagnild بود. نتايج حاصل از اين يُزوهش نشان داد كه تفاوت جنسيت بر تاب آناب

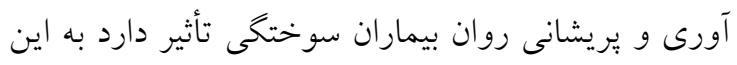

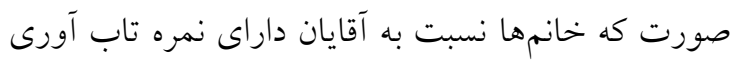

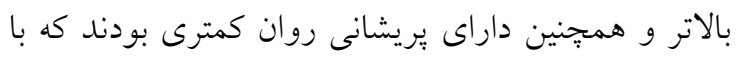
مطالعه حاضر همسو نبود. علت مشابه نبودن مىتواند به

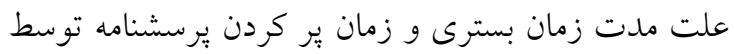

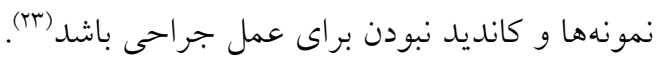

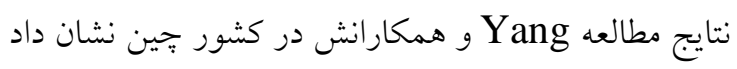
كه جنسيت، وضعيت تأهل، اشتغال، سطح تحصيلات

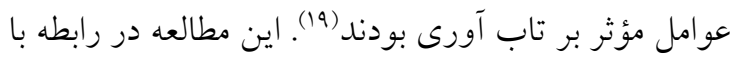

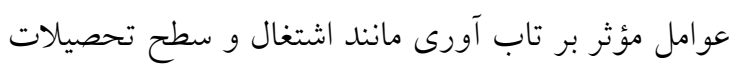

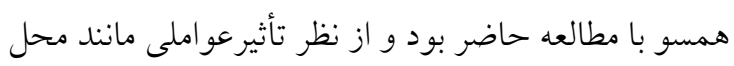

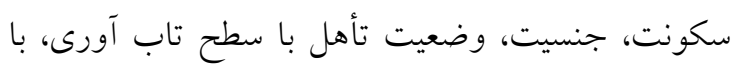
مطالعه حاضر مغايرت داشت. نتجه كلى مطالعه نشان داد

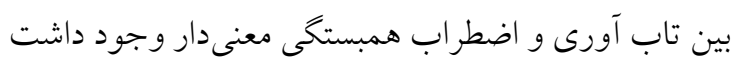

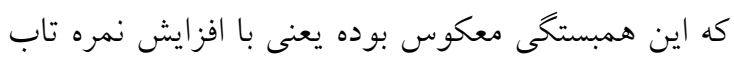

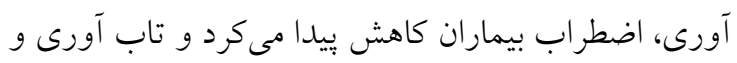

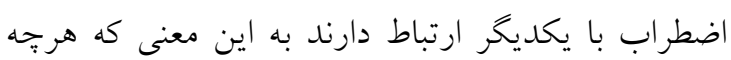
ميزان تاب آورى بالا تر باشد ميزان اضطراب كمتر مى شود.

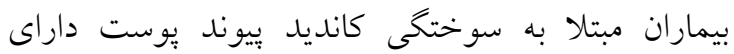

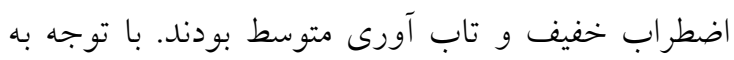

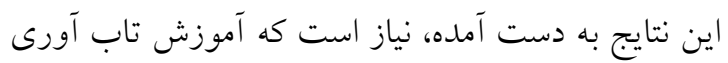
به عنوان يك اقدام مكمل در كنار ساير روشهاى دهايج درمانى

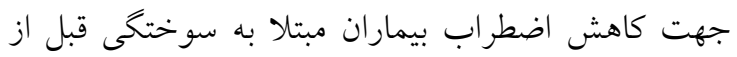
عمل جراحى ييوند يوست مورد استفاده قرار كيرد.

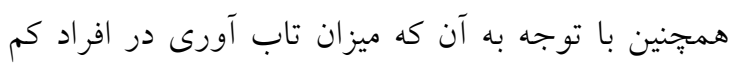

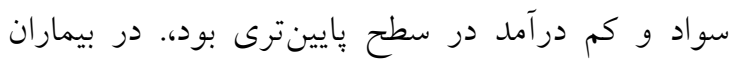




\section{References}

1. Hjemdal O, Vogel PA, Solem S, Hagen K, Stiles TC. The relationship between resilience and levels of anxiety, depression, and obsessive-compulsive symptoms in adolescents. Clinical psychology \& psychotherapy. 2011;18(4):314-21.

2. Thakrar S, Hunter TA, Medved MI, Hiebert-Murphy D, Brockmeier J, Sareen J, Logsetty S. Men, fire, and burns: Stories of fighting, healing, and emotions. Burns. 2015;41(8):1664-73.

3. Manzari ZS, Memariyan R, Vanaki Z. Effect of therapeutic communication on pain anxiety and burn wounds healing status. The Horizon of Medical Sciences. 2013;19(2):59-65. [Persian]

4. Ghanei Gheshlagh R, Dastras M, Fazlali PourMiyandoab M, Naseri O. The relationship between preoperative anxiety and postoperative nausea and vomiting. Medical Science Journal of Islamic Azad Univesity-Tehran Medical Branch. 2014;23(4):269-74. [Persian]

5. Bailey L. Strategies for decreasing patient anxiety in the perioperative setting. AORN journal. 2010;92(4):445-60.

6. Izadinia N, Amiri M, ghorban Jahromi R, Hamidi S. A study of relationship between suicidal ideas, depression, anxiety, resiliency, daily stresses and mental health among Tehran university students. Procedia-Soc Behav Sci. 2010;5:1615-9.

7. Bibi A, Kalim S, Khalid MA. Post-traumatic stress disorder and resilience among adult burn patients in Pakistan: a cross-sectional study. Burns \& trauma. 2018;6(1):8.

8. Connor KM, Davidson JR. Development of a new resilience scale: The Connor-Davidson resilience scale (CD-RISC). Depression and anxiety. 2003;18(2):76-82.

9. He F, Cao R, Feng Z, Guan H, Peng J. The impacts of dispositional optimism and psychological resilience on the subjective well-being of burn patients: A structural equation modelling analysis. PloS one. 2013;8(12):e82939.

10. Seyedoshohadaee M, Babaeeyan Kshtelee F, Seyyed Fatemi N, Saravi M, Haghani H. The Effect of Self-Care Education on the Resilience of the Patients With Heart Failure. Journal of ClientCentered Nursing Care. 2018;4(3):165-72. [Persian]

11. Saunders R, Singer R, Dugmore H, Seaman K, Lake F. Nursing students' reflections on an interprofessional placement in ambulatory care. Reflective Practice. 2016;17(4):393-402.

12. Benjamin DA, Jaco M. Burn nursing. InTotal burn care 2018 Jan 1 (pp. 355-363). Elsevier.

13. Beck AT, Epstein N, Brown G, Steer RA. An inventory for measuring clinical anxiety: psychometric properties. J Consult Clin Psychol. 1988;56(6):893.

14. Conner D. Managing at the speed of change: Guidelines for resilience in turbulent times. Villard Books; 1993.

15. Tol A, Pardel Shahri M, Esmaelee Shahmirzadi S, Mohebbi B, Javadinia SA. Effect of blended education program on anxiety among orthopedic patients surgery. J Nurs Educ. 2013;2(3):1-8.

16. Alvi T, Assad F, Malik MA. Anxiety and depression in burn patients. Journal of Ayub Medical College, Abbottabad: JAMC. 2009;21(1):137-41.

17. Matthias AT, Samarasekera DN. Preoperative anxiety in surgical patients-experience of a single unit. Acta Anaesthesiol Taiwan. 2012;50(1):3-6.

18. Palmu R, Suominen K, Vuola J, Isometsä E. Mental disorders after burn injury: a prospective study. Burns. 2011;37(4):601-9.

19. Yang Z, Wang JQ, Zhang BZ, Zeng Y, Ma HP. Factors influencing resilience in patients with burns during rehabilitation period. Int J Nurs Sci. 2014;1(1):97-101.

20. Ye ZJ, Qiu HZ, Li PF, Liang MZ, Zhu YF, Zeng Z, Hu GY, Wang SN, Quan XM. Predicting changes in quality of life and emotional distress in Chinese patients with lung, gastric, and colonrectal cancer diagnoses: the role of psychological resilience. Psycho-oncology. 2017;26(6):829-35.

21. Ghahremani $\mathrm{m}$, Khalatbari j. Relationship between hardiness resilience to anxiety on body dysmorphic concern in daughter adolescent city tehran. Quarterly Journal of Educational PsychologyIslamic Azad University Tonekabon Branch. 2017;8(03):74-85. [Persian]

22. Markovitz SE, Schrooten W, Arntz A, Peters ML. Resilience as a predictor for emotional response to the diagnosis and surgery in breast cancer patients. Psycho-oncology. 2015;24(12):1639-45.

23. Masood A, Masud Y, Mazahir S. Gender differences i.n resilience and psychological distress of patients with burns. Burns. 2016;42(2):300-6. 